\title{
The role of sex steroids in the regulation of insulin sensitivity and serum lipid concentrations during male puberty: a prospective study with a $\mathbf{P 4 5 0}$-aromatase inhibitor
}

\author{
Sanna Wickman, Tero Saukkonen and Leo Dunkel \\ Hospital for Children and Adolescents, University of Helsinki, PL281, FIN-O0O29 HUS, Helsinki, Finland
}

(Correspondence should be addressed to S Wickman; Email: sanna.wickman@helsinki.fi)

\begin{abstract}
Objective: Our purpose was to study the sex steroid-mediated changes in serum insulin and lipid concentrations in boys during puberty.

Design and Methods: We treated boys with constitutional delay of puberty either with testosterone plus placebo or with testosterone plus an aromatase inhibitor, letrozole, which inhibits the conversion of androgens to oestrogens. We demonstrated previously that during treatment with testosterone plus letrozole the increase in testosterone concentration was more than 5-fold higher than during treatment with testosterone plus placebo. The concentrations of $17 \beta$-oestradiol, IGF-I and IGFbinding protein-3 increased during testosterone-plus-placebo treatment, but during testosteroneplus-letrozole treatment the concentrations remained unchanged. These divergent changes in the two groups enabled us to study the effects of sex steroids and GH on insulin sensitivity and lipid concentrations.

Results: The insulin concentration in the testosterone-plus-placebo-treated group did not change. In contrast, in the testosterone-plus-letrozole-treated group, the concentration decreased during letrozole treatment, indicating improved insulin sensitivity. Changes in insulin and IGF-I concentrations within 12 and 18 months were correlated. In the testosterone-plus-placebo-treated group, the high-density lipoprotein cholesterol concentration did not change but in the testosterone-plusletrozole-treated group the concentration decreased. The concentrations of low-density lipoprotein cholesterol (LDL-cholesterol) and triglycerides did not change in either of the groups.

Conclusions: The findings indicate that androgens do not directly alter insulin sensitivity in boys during puberty. In contrast, the observations suggest tight regulation of glucose-insulin homeostasis by GH in boys at this stage. Furthermore, our findings indicate that sex steroids do not significantly participate in the regulation of serum concentrations of LDL-cholesterol or triglycerides in boys during early and mid-puberty.
\end{abstract}

European Journal of Endocrinology 146 339-346

\section{Introduction}

The metabolic syndrome consists of many interrelated cardiovascular risk factors, such as resistance to insulinstimulated glucose uptake and hyperinsulinaemia, hypertension, hypertriglyceridaemia, and decreased high-density lipoprotein cholesterol (HDL-cholesterol) concentration (1). Significant changes take place in these risk factors during adolescence simultaneously with the changes in body composition and in the concentrations of several hormones, including growth hormone (GH) and sex steroids.

In both sexes, insulin action is impaired and insulin secretion is increased during puberty (2-6). In healthy adolescents, insulin resistance has been demonstrated to correlate positively with concentrations of GH (2) and insulin-like growth factor-I (IGF-I) (3-5), suggesting that changes in insulin sensitivity during puberty may be due to the increasing action of GH. This concept is further supported by the development of insulin resistance and peripheral hyperinsulinaemia during $\mathrm{GH}$ treatment (7). The studies referred to above included both girls and boys. However, in crosssectional studies of adolescent boys only, insulin sensitivity did not correlate with parameters of $\mathrm{GH}$ secretion $(8,9)$. Instead, decreased insulin sensitivity was predicted from increases in the body mass index (BMI) and testosterone concentrations (8), or increases in total fat mass and Tanner stage (9). Furthermore, in seven prepubertal boys with delayed puberty, testosterone treatment did not impair insulin sensitivity, although IGF-I and mean nocturnal GH concentrations 
increased (10). Thus, the relative roles of sex steroids and $\mathrm{GH}$ in the puberty-associated alterations in insulin action and insulin secretion in boys has remained controversial.

In boys during puberty, the serum concentration of HDL-cholesterol decreases and that of triglycerides increases (11-13). An increase also occurs in the concentration of low-density lipoprotein cholesterol (LDL-cholesterol) (12, 13). A decrease in HDLcholesterol concentration in boys during puberty is related to an increase in testosterone concentration $(10,14-16)$. BMI is also negatively associated with HDL-cholesterol concentration in adolescent boys $(15,16)$. Concentrations of LDL-cholesterol and triglycerides have not been shown to correlate with testosterone but, instead, to be negatively associated with oestradiol concentration and positively associated with BMI (16). Thus, the concentrations of lipids in boys during adolescence appear to be regulated by many interrelated factors such as oestradiol, testosterone and BMI (13, 16, 17).

As the role of sex steroids in regulating the several cardiovascular risk factors associated with the metabolic syndrome in boys during puberty is unresolved, we set out to investigate the relative roles of oestrogens and androgens in the regulation of serum insulin and lipid concentrations in early and mid-pubertal boys. For this purpose, we studied boys with constitutional delay of puberty who were treated either with testosterone plus placebo or with testosterone plus a specific and potent aromatase inhibitor, letrozole, which inhibits the conversion of androgens to oestrogens.

\section{Materials and methods}

\section{Subjects}

The study population consisted of a group of 23 boys who were referred to the Hospital for Children and Adolescents, University of Helsinki, for evaluation of delayed puberty and/or short stature. The mean age of the boys was $15.1 \pm 0.2$ years (mean \pm s.e.m., range 13.5-16.1). Diagnosis of constitutional delay of puberty was defined as a Tanner genital or pubic hair stage observed at an age older than the mean +2 s.D. for healthy Finnish boys (18) or a testis volume of less than $4 \mathrm{ml}$ after 13.5 years of age. At entry, none of the boys had had any pubertal increase in growth velocity. Nor did medical history, clinical examination or routine laboratory tests reveal any signs of chronic illnesses to account for the delayed puberty in any of the boys. None of the boys had received any previous sex hormone treatment. One boy was receiving inhaled corticosteroid treatment for asthma.

\section{Protocol}

Informed written consent was obtained from the patients and from their guardians. The protocol was approved by the Ethical Committee of the Hospital for Children and Adolescents, and the National Agency for Medicines.

The boys were randomly assigned to receive one or other of the two treatments. The boys in the testosterone-plus-placebo-treated group (12 boys) received testosterone enanthate (Testoviron-Depot250; Schering, Berlin, Germany) at a dose of $1 \mathrm{mg} / \mathrm{kg}$ i.m. every 4 weeks six times and placebo orally once a day for 12 months. The testosterone-plus-letrozoletreated group (11 boys) received testosterone enanthate (as above) and, in addition, a specific and potent fourth-generation aromatase inhibitor, letrozole (Femar; Novartis AG, Stein, Switzerland), $2.5 \mathrm{mg}$ orally once a day for 12 months. The project was conducted as a double-blind, placebo-controlled study between the treated groups. The rationale for giving the boys this new P450-aromatase inhibitor was our hypothesis that this treatment, which inhibits oestrogen action, would help the boys to achieve their genetic height potential. The results reporting the effects of the two treatments on growth, bone maturation and concentrations of several hormones have been published previously (19). Ten boys in the testosterone-plusplacebo-treated group, and 11 boys in the testosterone-plus-letrozole-treated group completed the 2 month follow-up, 11 and 11 respectively the 5 month follow-up, 11 and 10 respectively the 12 month followup, and 10 and 10 respectively the 18 month followup. One boy in the testosterone-plus-letrozole-treated group was considered non-compliant, and therefore his results were excluded from the analyses.

Height, weight, fat-free body mass (FFM) and body fat mass (FM), and the concentrations of serum basal $17 \beta$-oestradiol, testosterone, insulin-like growth factor-I (IGF-I), IGF-binding protein-3 (IGFBP-3), total cholesterol, HDL-cholesterol, LDL-cholesterol and triglycerides were determined at the start, at 2 months (approximately 7 days after the third testosterone injection), at 5 months (approximately 7 days after the sixth testosterone injection), at 12 months and at 18 months. The serum basal insulin concentrations were determined at the start, at 5 months, at 12 months and at 18 months. All of the venous blood samples were drawn between 0730 and $1015 \mathrm{~h}$ mainly after a $12 \mathrm{~h}$ fast, but after at least a $10 \mathrm{~h}$ fast.

Height was measured on a Harpenden stadiometer to the nearest $0.1 \mathrm{~cm}$. Weight was measured with underwear on. The BMI was calculated from the formula: weight $(\mathrm{kg}) /$ height $^{2}\left(\mathrm{~m}^{2}\right)$. FFM, FM and percentage of FM reported in this study have been determined by bioelectrical impedance analysis. FFM was determined with an equation developed by Houtkooper (20). In this equation, predictor variables included height, body weight and resistance. We used impedance (which is a combination of resistance and reactance) in place of resistance, since the magnitude of the reactance is small relative to that of the resistance (21). FM 
was determined by subtracting FFM from weight. The percentage of body fat was also estimated from the sum of six skinfolds (22) in most of the boys from 2 months onwards. These percentages of body fat and the percentages of body fat measured by the bioelectrical impedance analyses correlated at each timepoint $(r=0.5-0.9, P=0.01-0.001)$ validating the measurements made by bioelectrical impedance analysis. We were able to determine the changes in FFM and FM within 2 months in eight boys in the group treated with testosterone plus placebo and in ten boys in the group treated with testosterone plus letrozole, within 5 months in nine and in ten boys, but within 12 months only in six and in nine boys, and within 18 months only in six and in seven boys respectively.

\section{Hormone measurements}

Serum $17 \beta$-oestradiol concentrations were determined by a modified RIA, using coated tube technology (Spectria oestradiol; Orion Diagnostica, Espoo, Finland) after diethyl ether extraction $(700 \mu \mathrm{l}$ serum plus $5 \mathrm{ml}$ diethyl ether) (23). The detection limit of the assay was $6 \mathrm{pmol} / \mathrm{l}$. Serum testosterone concentrations were measured by RIA after separation of steroid fractions on a Lipidex-5000 microcolumn (Packard-Becker, BV Chemical Operations, Groningen, The Netherlands) (24). Serum IGF-I and IGFBP-3 concentrations were determined by RIAs (DiaSorin, Stillwater, MN, USA and Nichols Institute Diagnostics, San Juan Capistrano, CA, USA respectively). Serum insulin concentrations were determined by RIA (Pharmacia \& Upjohn Diagnostics AB, Uppsala, Sweden). Concentrations of serum total cholesterol, HDL-cholesterol and triglycerides were determined by enzymatic colorimetric tests (Roche Diagnostics GmbH, Mannheim, Germany). Serum LDL-cholesterol concentrations were calculated using the equation of Friedewald et al. (25).

\section{Statistical analysis}

All values are expressed as means \pm S.E.M. Analyses were conducted with the SPSS statistical software for Windows, Release 8.0.2 (SPSS Inc., Chicago, IL,
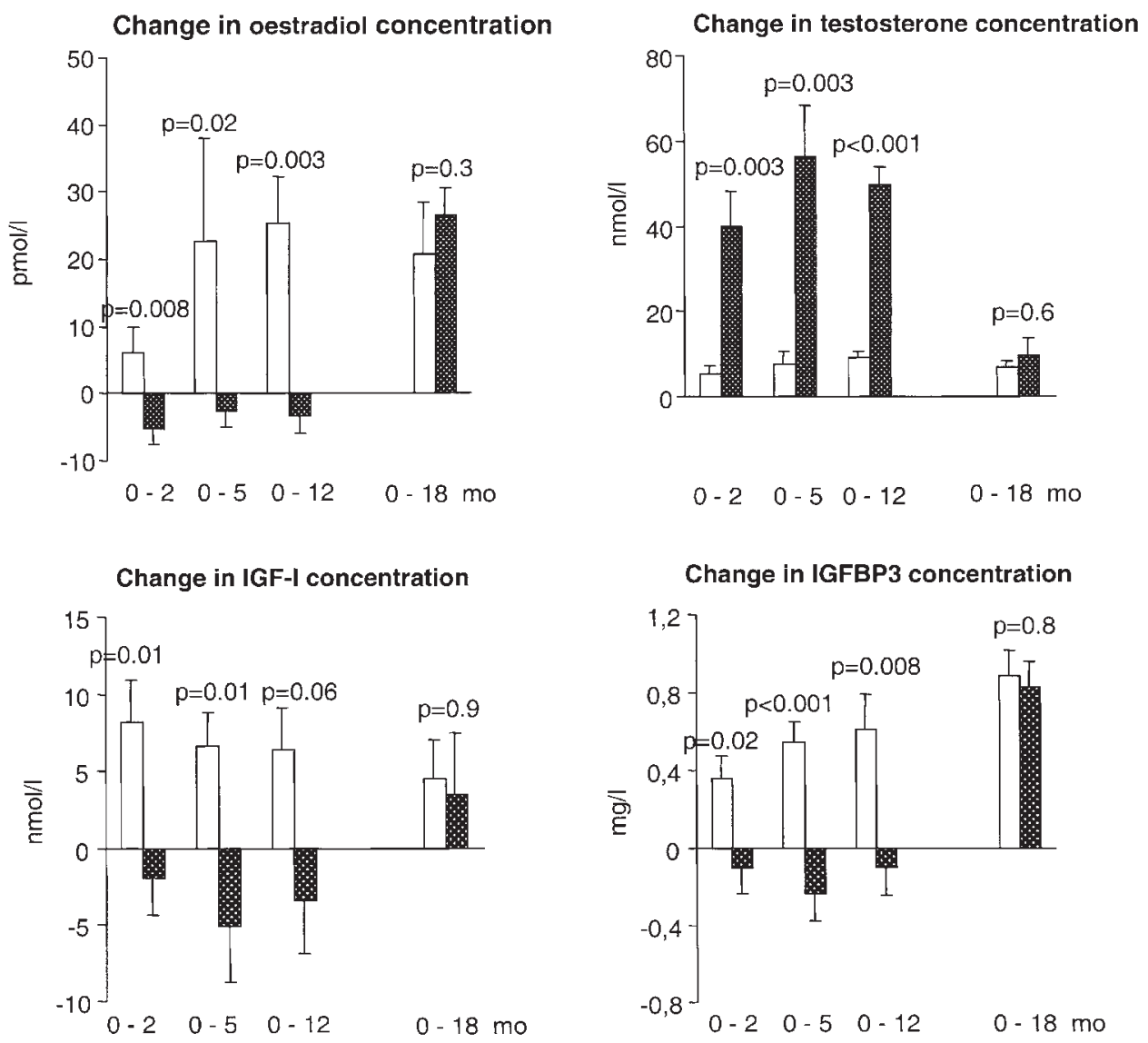

Figure 1 Mean \pm S.E.M. changes in serum 17ß-oestradiol, testosterone, IGF-I and IGFBP-3 concentrations in the testosteroneplus-placebo-treated (empty columns) and in the testosterone-plus-letrozole-treated (filled columns) groups. The boys received testosterone for 5 months and letrozole or placebo for 12 months. Student's unpaired $t$-test or the Mann-Whitney $U$ test was used. The absolute values of the concentrations have been published previously (19). 
USA). Student's paired $t$-test or the Wilcoxon matched pairs signed-rank sum test was used for analyses of the changes within groups during the follow-up. For analysis of serial measurements, the summary measures, i.e. the differences from the start, were calculated for each subject, and these values were treated as raw data for the appropriate statistical analysis. Student's unpaired $t$-test or the Mann-Whitney U test was used as appropriate. The correlations between changes in insulin concentrations and changes in BMIs, concentrations of $17 \beta$-oestradiol, testosterone, IGF-I and IGFBP-3 were studied. The correlations between changes in concentrations of HDL-cholesterol and changes in BMIs, concentrations of $17 \beta$-oestradiol, testosterone, IGF-I and IGFBP-3 were also determined. Pearson's or Spearman's correlation coefficients were used. All statistical tests were two-sided. A $P$ value of less than 0.05 was considered statistically significant.

\section{Results}

At the start of the follow-up, the groups did not differ in the concentrations of serum $17 \beta$-oestradiol, testosterone, IGF-I, IGFBP-3, insulin, HDL-cholesterol, LDLcholesterol or triglycerides, or in BMI, FFM, FM or percentage of FM.

\section{Concentrations of serum 17 $\beta$-oestradiol, testosterone, IGF-I and IGFBP-3}

The 17ß-oestradiol, testosterone, IGF-I and IGFBP-3 concentrations have been published previously (19). During the treatments these concentrations changed differently in the two groups (Fig. 1). The $17 \beta$-oestradiol concentration in the testosterone-plus-placebotreated group increased during the treatment, whereas

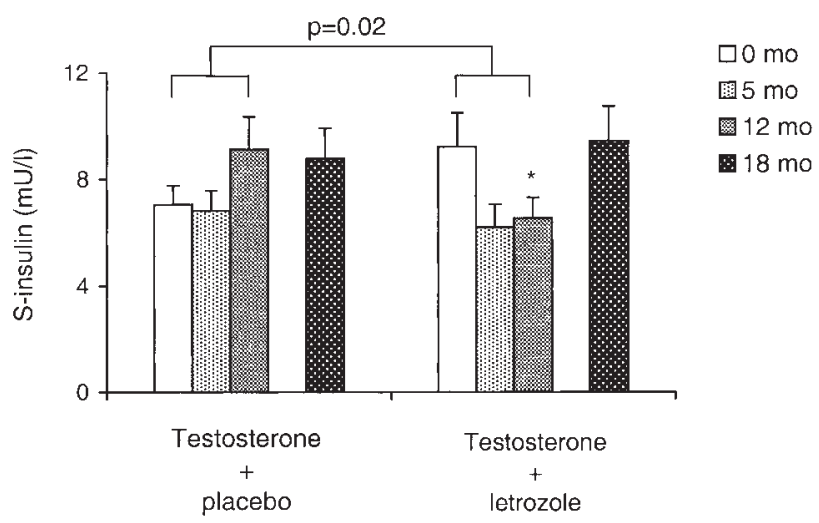

Figure 2 Mean \pm S.E.M. serum insulin concentrations during the follow-up. The boys received testosterone for 5 months and letrozole or placebo for 12 months. ${ }^{*} P=0.04$ (Student's paired $t$-test) within the group as compared with the start. Student's unpaired $t$-test was used to analyse the difference regarding changes in insulin concentration within 12 months between the treated groups. in the testosterone-plus-letrozole-treated group it remained at the pretreatment level until discontinuation of letrozole treatment at 12 months. The testosterone concentrations increased in both groups, but in the testosterone-plus-letrozole-treated group the increases within 2,5 and 12 months were more than 5-fold higher than in the testosteroneplus-placebo-treated group. The IGF-I and IGFBP-3 concentrations in the testosterone-plus-placebo-treated group increased immediately after the start of the treatment, but in the testosterone-plus-letrozole-treated group the concentrations remained unchanged during the treatment.

\section{Concentrations of serum insulin}

In the testosterone-plus-placebo-treated group, there was no change in insulin concentration during the follow-up (Fig. 2). In contrast, in the testosteroneplus-letrozole-treated group, the insulin concentration decreased during letrozole treatment $(P=0.04$, within 12 months), but, after discontinuation of letrozole treatment, increased to the pretreatment level. The changes in insulin concentration within 12 months in the two groups were different $(P=0.02)$.

The changes in serum insulin and IGF-I concentrations within 12 and 18 months were correlated $(r=0.5, P=0.04$ for both; Fig. 3). No correlations between the changes in insulin concentrations and the changes in IGFBP-3, 17 $\beta$-oestradiol, or testosterone concentrations, or in BMI were observed.

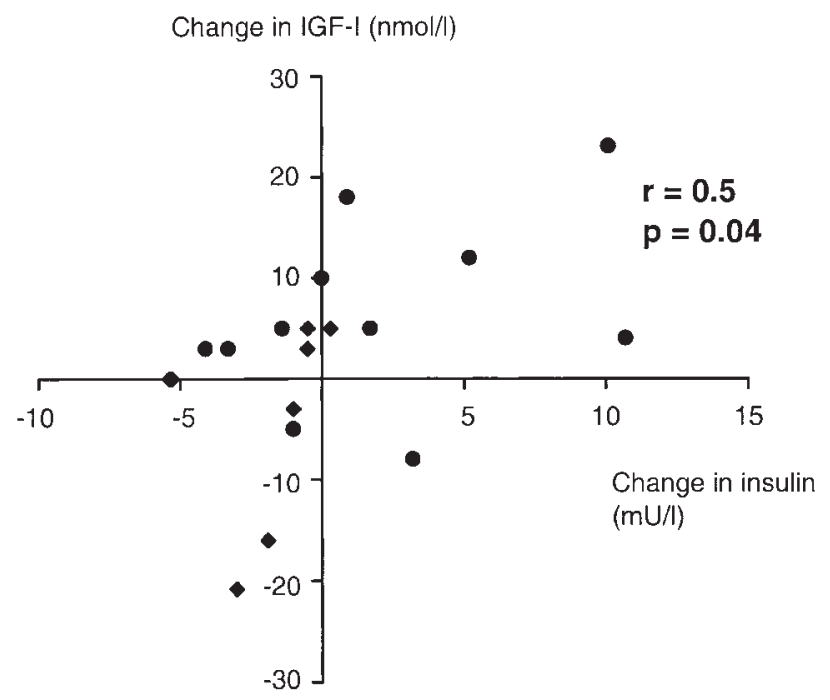

Figure $3 \mathrm{~A}$ correlation (Pearson correlation) between changes in serum insulin concentration and changes in serum IGF-I concentration within 12 months. $\bullet$, Boys who received testosterone for 5 months and placebo for 12 months; $\bullet$, boys who received testosterone for 5 months and letrozole for 12 months. 


\section{Body composition}

In the testosterone-plus-placebo-treated group, the BMI did not change during the follow-up (Fig. 4). In the testosterone-plus-letrozole-treated group, the BMI increased after the start of the treatment $(P=0.01$, within 2 months), and decreased to the pretreatment level only after discontinuation of letrozole treatment at 18 months. Thus, the changes in BMI in the groups were different at 2,5 and 12 months $(P=0.005,0.001$ and 0.003 respectively).

There were no differences between the groups in increases of FFM. The decreases in FM and in the percentage of FM were more profound in the testosterone-plus-placebo-treated group than in the testosterone-plus-letrozole-treated group within 5 months, but similar at the other time-points.

\section{Concentrations of serum HDL- and LDL-cholesterol and triglycerides}

The HDL-cholesterol concentration in the testosteroneplus-placebo-treated group did not change during the follow-up (Fig. 5). In contrast, in the testosteroneplus-letrozole-treated group, the HDL-cholesterol concentration decreased already at 2 months after the start of treatment $(P=0.01)$, and the concentrations at 5, 12 and 18 months were also lower than the concentration at the start. The changes in the HDLcholesterol concentration in the groups differed at 5 months $(P=0.005)$, and were borderline different at 12 months $(P=0.06)$. After discontinuation of all treatments at 18 months, the concentrations were similar in the two groups. Changes in HDL-cholesterol concentrations correlated negatively with changes in BMIs $(r=-0.6, P=0.01$ within 2 months; $r=-0.6$, $P=0.004$ within 5 months; $r=-0.4, P=0.08$ within 12 months), negatively with changes in testosterone concentrations $(r=-0.6, \quad P=0.007$ within 2 months; $r=-0.6, P=0.004$ within 5

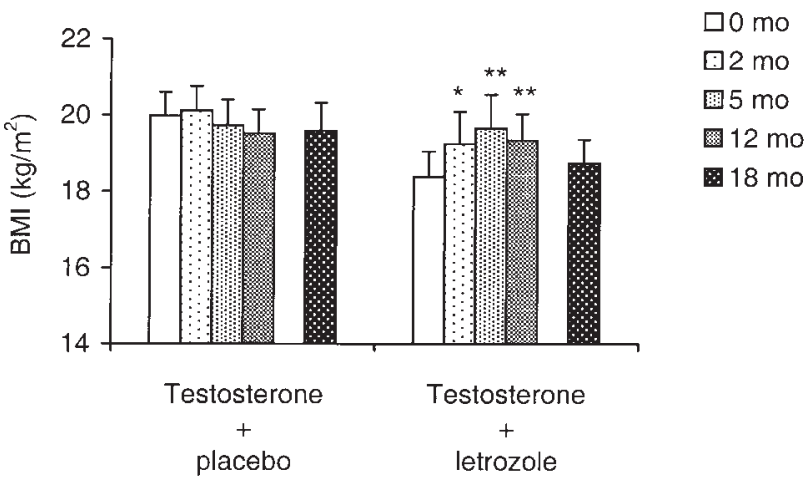

Figure 4 Mean \pm S.E.M. of BMls during the follow-up. The boys received testosterone for 5 months and letrozole or placebo for 12 months. ${ }^{\star} P=0.01,{ }^{\star *} P<0.01$ within the group as compared with the start (Student's paired $t$-test). months; $r=-0.4, \quad P=0.09$ within 12 months), positively with changes in IGF-I concentrations ( $r=0.5, P=0.01$ within 5 months), and positively with changes in IGFBP-3 concentrations $(r=0.6$, $P=0.005$ within 5 months; $r=0.4, \quad P=0.07$ within 18 months).

The concentrations of LDL-cholesterol or triglycerides did not change during the follow-up in either group (Fig. 5).

\section{Discussion}

In this randomised, prospective study of two alternative treatments for boys with constitutional delay of puberty, we found divergent changes in the concentrations of sex steroids and in the parameters reflecting $\mathrm{GH}$ secretion in the two groups (19). This enabled us to study the effects of sex steroids and GH on insulin sensitivity and serum lipid concentrations during male puberty.

Fasting insulin concentration, which we used as an index of insulin resistance, has been demonstrated to correlate well with insulin resistance measured by the euglycaemic insulin clamp technique (26). In the testosterone-plus-placebo-treated group, the insulin concentration did not change, but in the testosteroneplus-letrozole-treated group, the concentration decreased during letrozole treatment, suggesting an improvement in insulin sensitivity in the latter group. It is noteworthy that insulin concentrations decreased during letrozole treatment, despite a more than 5-fold higher increase in the mean testosterone concentration in this group. This finding indicates that an increase in the concentration of androgens during puberty does not contribute significantly to the development of insulin resistance in boys. That the role of oestrogens in the regulation of glucose-insulin homeostasis in males is insignificant is suggested by our observation that changes in $17 \beta$-oestradiol concentrations were not correlated with changes in insulin concentrations and by the finding that insulin and glucose concentrations in late pubertal and young adult males did not change despite a 10 week aromatase inhibition with anastrozole (27). Since no pubertal increases in IGF-I or IGFBP-3 concentrations were observed during letrozole treatment, the decrease in insulin concentrations during letrozole treatment may have been due to the suppression of GH secretion. This suggestion is further supported by the finding that the changes in insulin concentration correlated positively with the changes in IGF-I concentration. These observations suggest tight regulation of glucose-insulin homeostasis by GH in pubertal boys. Thus, a decrease in insulin sensitivity in boys during adolescence may result from the increasing action of $\mathrm{GH}$; this has previously been demonstrated in groups of adolescents composed of both sexes $(2-5,7)$. Although androgens may not 
Serum HDL-cholesterol

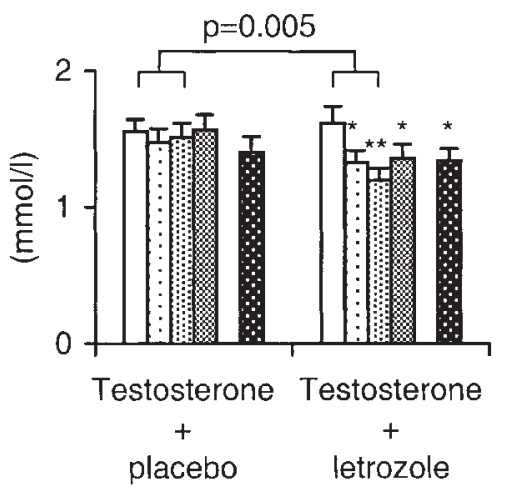

Serum LDL-cholesterol

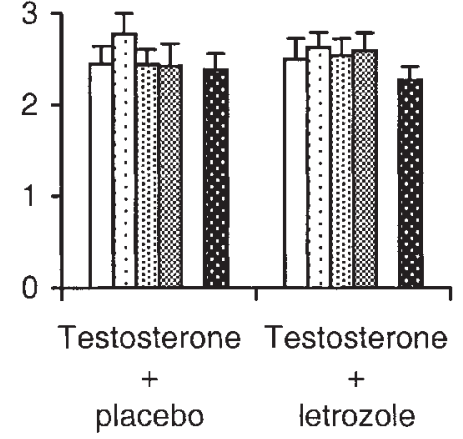

Serum triglycerides

$\square 0 \mathrm{mo}$

$\square 2 \mathrm{mo}$

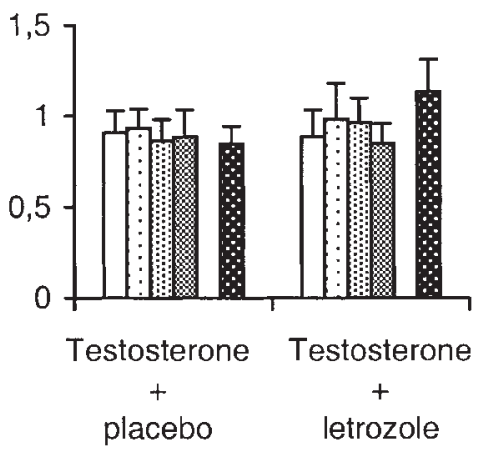

Figure 5 Mean \pm S.E.M. concentrations of serum HDL-cholesterol, LDL-cholesterol and triglycerides during the follow-up. The boys received testosterone for 5 months and letrozole or placebo for 12 months. ${ }^{*} P<0.05$, ${ }^{* \star} P<0.01$ within the group as compared with the start (Student's paired $t$-test). Student's unpaired $t$-test was used to analyse the difference regarding changes in HDL-cholesterol concentration between the treated groups within the first 5 months.

directly regulate the development of insulin resistance during puberty, they may do so indirectly through conversion of androgens to oestrogens, which in turn stimulate GH secretion (28).

In the testosterone-plus-placebo-treated group, BMI did not change. In contrast, in the testosterone-plusletrozole-treated group, an increase in BMI was seen during letrozole treatment. Thus, the decrease in insulin concentration during letrozole treatment was obviously not a consequence of decreased body mass; furthermore, the percentage of FM did not decrease more during testosterone-plus-letrozole than during testosterone-plus-placebo treatment. Our observation that BMI increased simultaneously with the decrease in insulin concentration contrasts with a previous finding of a negative association between BMI and insulin sensitivity in adolescent boys (8). This discrepancy may be explained by the fact that BMI is a poor indicator of obesity. An increased amount of body fat is associated with impaired insulin sensitivity, but an increase in BMI may also be due to an increase in the amount of lean body mass. In fact, in the testosterone-plus-letrozole-treated group, FFM increased simultaneously with the increase in BMI.

The HDL-cholesterol concentration decreased more in the testosterone-plus-letrozole-treated group than in the testosterone-plus-placebo-treated group. Changes in HDL concentration correlated most strongly with changes in testosterone concentration and in BMI. This is in accord with the concept that androgens contribute to the puberty-associated decrease in HDL concentration $(10,14-16)$. The observation also supports the importance of body composition in the regulation of HDL-cholesterol concentration in boys during puberty $(15,16)$. However, a decrease in HDL cholesterol concentration in the testosterone-plus-letrozole-treated group may also partly have resulted from inhibition of the action of oestrogens. In adult men, suppression of the action of endogenous oestrogens by testolactone, an aromatase inhibitor, decreased HDL-cholesterol concentrations (29). Moreover, in men in whom oestrogen action was suppressed by mutations in the gene for the enzyme P450-aromatase, their subnormal HDL-cholesterol concentrations normalised during oestrogen treatment (30-32). In contrast to this, in adolescent boys, HDL-cholesterol concentrations do not correlate with oestradiol concentrations (16). In our study, changes in HDL-cholesterol concentrations did not correlate with changes in $17 \beta$-oestradiol concentrations. This may indicate that, in males, oestrogens contribute significantly to the regulation of HDL-cholesterol metabolism only after puberty.

In our study groups, the concentrations of LDLcholesterol and triglycerides did not change, despite the significant differences in the concentrations of $17 \beta$-oestradiol and testosterone between the groups. This is in contrast to a previous finding of a negative association between oestradiol and LDL-cholesterol or triglycerides in a group of adolescent boys from preto late puberty (16). The importance of oestrogens in the regulation of metabolism of LDL-cholesterol and triglycerides in males is further supported by the findings in adult men with the P450-aromatase mutation, whose high concentrations of LDL-cholesterol and triglycerides decreased during oestrogen treatment (30-32). Low-dose 17 $\beta$-oestradiol administration to elderly men also decreased their concentrations of LDL-cholesterol and triglycerides (33). The discrepancy between our results and previous findings may be due to the fact that the roles of sex steroids in the regulation of lipid metabolism vary in different age groups (34). Our results suggest that sex steroids do not contribute significantly to the regulation of the serum concentrations of LDL-cholesterol and triglycerides in boys during early and mid-puberty. Whether oestrogens 
participate in the regulation of LDL-cholesterol and triglyceride metabolism in late puberty, as they do in adult men (30-33), and whether sex steroids contribute to the increase in LDL-cholesterol that occurs in late puberty in boys (12), remain to be clarified.

The results of this prospective study with a P450-aromatase inhibitor suggest that androgens do not directly participate significantly in the regulation of insulin sensitivity in boys during puberty. In contrast, our observations confirm the importance of $\mathrm{GH}$ in the development of pubertal insulin resistance in boys. Moreover, our observations indicate that serum concentrations of LDL-cholesterol and triglycerides are not regulated by sex steroids in boys during early and mid-puberty.

\section{Acknowledgements}

This study was supported by the Foundation for Paediatric Research, Helsinki, Finland.

We gratefully acknowledge the help of Carina Ankarberg-Lindgren and Ensio Norjavaara, of Göteborg Paediatric Growth Research Centre, Göteborg University, Sweden, for performing the $17 \beta$-oestradiol assays.

\section{References}

1 Reaven GM. Role of insulin resistance in human disease. Diabetes $1988371595-1607$.

2 Amiel SA, Sherwin RS, Simonson DC, Lauritano AA \& Tamborlane WV. Impaired insulin action in puberty. A contributing factor to poor glycemic control in adolescents with diabetes. New England Journal of Medicine 1986315 215-219.

3 Bloch CA, Clemons P \& Sperling MA. Puberty decreases insulin sensitivity. Journal of Pediatrics $1987110481-487$.

4 Caprio S, Plewe G, Diamond MP, Simonson DC, Boulware SD, Sherwin RS et al. Increased insulin secretion in puberty: a compensatory response to reductions in insulin sensitivity. Journal of Pediatrics $1989114963-967$.

5 Smith CP, Dunger DB, Williams AJK, Taylor AM, Perry LA, Gale EAM et al. Relationship between insulin, insulin-like growth factor I, and dehydroepiandrosterone sulfate concentrations during childhood, puberty, and adult life. Journal of Clinical Endocrinology and Metabolism 198968 932-937.

6 Amiel SA, Caprio S, Sherwin RS, Plewe G, Haymond MW \& Tamborlane WV. Insulin resistance of puberty: a defect restricted to peripheral glucose metabolism. Journal of Clinical Endocrinology and Metabolism 199172 277-282.

7 Heptulla RA, Boulware SD, Caprio S, Silver D, Sherwin RS \& Tamborlane WV. Decreased insulin sensitivity and compensatory hyperinsulinemia after hormone treatment in children with short stature. Journal of Clinical Endocrinology and Metabolism $1997 \mathbf{8 2}$ 3234-3238.

8 Cook JS, Hoffman RP, Stene MA \& Hansen JR. Effects of maturational stage on insulin sensitivity during puberty. Journal of Clinical Endocrinology and Metabolism 199377 725-730.

9 Travers SH, Jeffers BW, Bloch CA, Hill JO \& Eckel RH. Gender and Tanner stage differences in body composition and insulin sensitivity in early pubertal children. Journal of Clinical Endocrinology and Metabolism $1995 \mathbf{8 0} 172-178$.

10 Arslanian S \& Suprasongsin C. Testosterone treatment in adolescents with delayed puberty: changes in body composition, protein, fat, and glucose metabolism. Journal of Clinical Endocrinology and Metabolism 199782 3213-3220.

11 Morrison JA, deGroot I, Edwards BK, Kelly KA, Mellies MJ, Khoury $\mathrm{P}$ et al. Lipids and lipoproteins in 927 schoolchildren, ages 6 to 17 years. Pediatrics 197862 990-995.

12 Morrison JA, Laskarzewski PM, Rauh JL, Brookman R, Mellies M, Frazer M et al. Lipids, lipoproteins, and sexual maturation during adolescence: the Princeton maturation study. Metabolism 1979 28 641-649.

13 Laskarzewski PM, Morrison JA, Gutai J, Khoury PR \& Glueck CJ. Longitudinal relationships among endogenous testosterone, estradiol, and Quetelet index with high and low density lipoprotein cholesterols in adolescent boys. Pediatric Research 1983 $17689-698$.

14 Kirkland RT, Keenan BS, Probstfield JL, Patsch W, Lin TL, Clayton GW et al. Decrease in plasma high-density lipoprotein cholesterol levels at puberty in boys with delayed adolescence. Correlation with plasma testosterone levels. Journal of the American Medical Association $1987 \mathbf{2 5 7} 502-507$.

15 Morrison JA, Sprecher DL, Biro FM, Hansen CA, Lucky AW \& Wride K. Sex hormones and lipoproteins in adolescent male offspring of parents with premature coronary heart disease and a control group. Journal of Pediatrics 1998133 526-532.

16 Morrison JA, Sprecher DL, Biro FM, Apperson-Hansen C, Lucky AW \& DiPaola LM. Estradiol and testosterone effects on lipids in black and white boys aged 10 to 15 years. Metabolism $2000 \mathbf{4 9}$ 1124-1129.

17 Laskarzewski PM, Morrison JA, Gutai J, Orchard T, Khoury PR \& Glueck CJ. High and low density lipoprotein cholesterols in adolescent boys: relationships with endogenous testosterone, estradiol, and Quetelet index. Metabolism 198332 262-271.

18 Ojajärvi P. The adolescent Finnish child, a longitudinal study of the anthropometry, physical development and physiological changes during puberty. Thesis. University of Helsinki, 1982.

19 Wickman S, Sipilä I, Ankarberg-Lindgren C, Norjavaara E \& Dunkel L. A specific aromatase inhibitor and potential increase in adult height in boys with delayed puberty: a randomised controlled trial. Lancet 2001357 1743-1748.

20 Houtkooper LB, Going SB, Lohman TG, Roche AF \& Van Loan M. Bioelectrical impedance estimation of fat-free body mass in children and youth: a cross-validation study. Journal of Applied Physiology 199272 366-373.

21 Lukaski HC, Johnson PE, Bolonchuk WW \& Lykken GI. Assessment of fat-free mass using bioelectrical impedance measurements of the human body. American Journal of Clinical Nutrition $1985 \mathbf{4 1} 810-817$.

22 Anyan WR Jr. Adolescent Medicine in Primary Care, pp 135-138. New York: John Wiley \& Sons, 1978.

23 Norjavaara E, Ankarberg C \& Albertsson-Wikland K. Diurnal rhythm of 17 beta-estradiol secretion throughout pubertal development in healthy girls: evaluation by a sensitive radioimmunoassay. Journal of Clinical Endocrinology and Metabolism $1996814095-4102$.

24 Apter D, Jänne O, Karvonen P \& Vihko R. Simultaneous determination of five sex hormones in human serum by radioimmunoassay after chromatography on Lipidex-5000. Clinical Chemistry 197622 32-38.

25 Friedewald WT, Levy RI \& Fredrickson DS. Estimation of the concentration of low-density lipoprotein cholesterol in plasma, without use of the preparative ultracentrifuge. Clinical Chemistry $197218499-502$.

26 Olefsky J, Farquhar JW \& Reaven G. Relationship between fasting plasma insulin level and resistance to insulin-mediated glucose uptake in normal and diabetic subjects. Diabetes 197322 507-513.

27 Mauras N, O’Brien KO, Klein KO \& Hayes V. Estrogen suppression in males: metabolic effects. Journal of Clinical Endocrinology and Metabolism 200085 2370-2377.

28 Metzger DL \& Kerrigan JR. Estrogen receptor blockade with tamoxifen diminishes growth hormone secretion in boys: evidence for a stimulatory role of endogenous estrogens during 
male adolescence. Journal of Clinical Endocrinology and Metabolism $199479513-518$.

29 Bagatell CJ, Knopp RH, Rivier JE \& Bremner WJ. Physiological levels of estradiol stimulate plasma high density lipoprotein-2 cholesterol levels in normal men. Journal of Clinical Endocrinology and Metabolism 199478 855-861.

30 Morishima A, Grumbach MM, Simpson ER, Fisher C \& Qin K. Aromatase deficiency in male and female siblings caused by a novel mutation and the physiological role of estrogens. Journal of Clinical Endocrinology and Metabolism $1995 \mathbf{8 0}$ 3689-3698.

31 Bilezikian JP, Morishima A, Bell J \& Grumbach MM. Increased bone mass as a result of estrogen therapy in a man with aromatase deficiency. New England Journal of Medicine 1998339 599-603.
32 Carani C, Qin K, Simoni M, Faustini-Fustini M, Serpente S, Boyd J et al. Effect of testosterone and estradiol in a man with aromatase deficiency. New England Journal of Medicine 1997337 91-95.

33 Giri S, Thompson PD, Taxel P, Contois JH, Otvos J, Allen R et al. Oral estrogen improves serum lipids, homocysteine and fibrinolysis in elderly men. Atherosclerosis 1998137 359-366.

34 Srinivasan SR, Freedman DS, Sundaram GS, Webber LS \& Berenson GS. Racial (black-white) comparisons of the relationship of levels of endogenous sex hormones to serum lipoproteins during male adolescence: the Bogalusa Heart Study. Circulation $1986741226-1234$.

Received 22 June 2001

Accepted 6 December 2001 